\title{
Proposta de Ensino Individualizado para Estudantes com Autismo: Uma Abordagem com Dispositivos Móveis
}

\author{
Maria do Desterro Fernandes de Araujos ${ }^{1}$, Martony Demes da Silva ${ }^{2}$
}

Curso de Licenciatura em Computação - Universidade Federal do Piauí (UFPI) Universidade Aberta do Brasil (UAB) - Polo de Castelo do Piauí

Castelo do Piauí - PI- Brasil

mayte_fernandes@hotmail.com,mardemes@gmail.com

Abstract. Autism is a Global Developmental Disorder that mainly affects the individual's behavior and communication. Therefore, teaching students with this disorder requires specific and individualized alternative strategies. This research aims to present a teaching proposal with the use of mobile devices for the monitoring and evolution of the individual and based on the analysis of the applied activity. It is expected that the individual can evolve and build a consistent repertoire. And the educator is able to systematically accompany each student with autism..

Resumo. Autismo é um Transtorno Global do Desenvolvimento que afeta principalmente o comportamento e a comunicação do indivíduo. Diante disso, o ensino de estudante com tal transtorno requer estratégias alternativas especificas e individualizadas. Esta pesquisa objetiva apresentar uma proposta de ensino com uso de dispositivos móveis para o acompanhamento e evolução do individual e com base na análise da atividade aplicada. Espera-se que o indivíduo possa evoluir e construir um repertório consistente. E o educador consiga acompanhar sistematicamente cada estudante com autismo.

\section{Introdução}

O ensino de estudante com autismo apresenta-se como um grande desafio para as escolas em salas de aulas regulares. Isso se deve a variabilidade dos sintomas que acomete o indivíduo com Transtorno do Espectro Autista (TEA). As tecnologias assistivas representam "os recursos que visam a expansão de possibilidades dos portadores de necessidades especiais" (Gomes, Varella \& de Souza, 2010)

O TEA possui uma definição sobre indivíduos que, segundo o DSM-V (2014) é caracterizado por déficits na comunicação e interação social em diversos contextos.

Nesse contexto, os sintomas do TEA podem variar entre leve, moderado e severo, o que resulta em níveis de suportes diferentes para cada comportamento acometido pelo transtorno (APA, 2013; Pimentel, 2013). Isso vale também para o ensino e aprendizagem. Diante disso, o desafio é ensinar para esses indivíduos que estão em um espectro de variabilidade de características.

Dentre as estratégias de ensino para a inclusão de estudante com TEA, já evidenciou-se a necessidade de prover um ensino de qualidade valorizando as diferenças individuais e respeite o ritmo de aprendizagem individual de cada estudante [GOMES, DA SILVA CARVALHO, DE SOUZA, 2014]. 
Nesse conjectura, as tecnologias podem ser utilizadas como ferramentas auxiliadoras no processo de acessibilidade e inclusão. Elas visam integração capaz de atender e auxiliar alunos com necessidades educacionais especiais.

Diante disso, esta pesquisa apresenta uma proposta de ensino individualizado para estudante com autismo com uso de dispositivos móveis. A estratégia visa acompanhar e avaliar a evolução individual e com base na atividade aplicada. Dessa forma, almeja-se que o indivíduo possa evoluir seu repertório de ensino. Além disso, o professor consiga acompanhar sistematicamente cada estudante com autismo.

O diferencial deste trabalho é que a possibilidade de acompanhar e gerenciar via software as atividades de ensino de cada criança com autismo. Isso proverá inclusão desses estudantes com autismo no contexto da cidade de Juazeiro do Piauí.

\section{Referencial Teórico}

O uso de abordagens de ensino com tecnologias para ensino de crianças com autismo já vem sendo abordado no âmbito da pesquisa científica. No bojo deste trabalho, destacou-se alguns trabalhos relevantes. Por exemplo, o estudo sobre a necessidade de incluir crianças na escola de modelo inclusivo [ALVES,LISBOA,LISBOA, 2010]. A pesquisa mostra em seus resultados que o indivíduo autista pode ser tratado e desenvolver suas habilidades de uma forma muito mais intensiva.

Já o artigo de [DEMES, SOARES, BENITEZ, 2017], é apresentado um ambiente digital denominado como mTEA para aplicação de programas de ensino por tentativas discretas, fundamentados na perspectiva comportamental. Os resultados mostraram-se satisfatório com uso de tablet com grupo de cinco crianças com autismo.

Por outro lado, a abordagem de [Farias, Silva, \& Cunha, 2014], apresenta um software para auxiliar a alfabetização de crianças autistas. A proposta faz uso da metodologia TEACH. As atividades são as mesmas para todos os níveis de autismo.

No trabalho de [Carvalho e Cunha, 2019], é apresentado um aplicativo móvel para ensino de estudantes com autismo. A limitação desse trabalho é que apenas uso da disciplina matemática. Outro trabalho relevante é apresentado por [BITTENCOURT e FUMES, 2016]. Nessa pesquisa, é abordado o software SCALA que visa apoiar o letramento de estudantes com autismo.

Em síntese, a Tabela 1, apresenta, os trabalhos selecionados. Verifica-se que nenhuma das pesquisas citadas propõe gerenciamento de atividades e com tecnologia móvel. Esta pesquisa propõe acompanhar a evolução de ensino de atividades no ambiente digital para estudantes com autismo.

Tabela 1: Levantamento bibliográfico da pesquisa

\begin{tabular}{|l|l|l|}
\hline Trabalhos & Tecnologia & Gerência ativ. \\
\hline [ALVES,LISBOA,LISBOA 2010] & Não citado & Não \\
\hline [DEMES, SOARES, BENITEZ, 2017] & Mobile & Não \\
\hline [Farias, Silva, \& Cunha, 2014] & Mobile & Não \\
\hline [BITTENCOURT e FUMES, 2016] & Computador & Não \\
\hline Proposta desta pesquisa & Mobile & Sim \\
\hline
\end{tabular}




\section{Metodologia (evolução da metodologia)}

A estratégia que visa mitigar o problema citado nesta pesquisa, ensino individualizado para estudante com autismo, é utilizar software para dispositivos móveis. Para detalhar a estratégia, a pesquisa dividiu o método em três etapas, conforme apresentado a seguir.

\subsection{Etapas}

$1^{a}$ etapa: Será feito um estudo e levantamento da sobre as características os estudantes com autismo na cidade de Juazeiro do Piauí.

$2^{\mathbf{a}}$ etapa: Será feito uma avaliação com crianças com autismo utilizando os softwares citados como referência nesta pesquisa.

$3^{\text {a }}$ etapa: Será desenvolvido um ambiente digital para aplicação de atividades de ensino com crianças com autismo. O diferencial desse ambiente é a possibilidade de gerenciar a evolução das crianças para tomar decisão em atividades futuras.

A Figura 1, a seguir, ilustra o diagrama representativo desta metodologia.

O Diagrama a seguir apresenta uma ilustração da proposta de pesquisa.

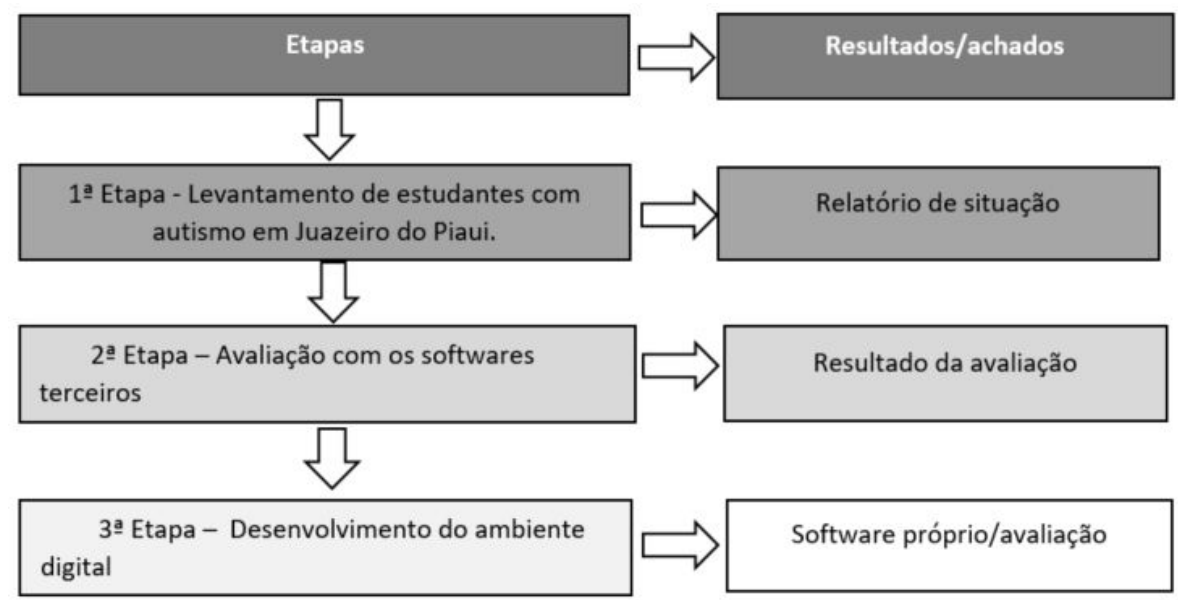

Figura 1: Diagrama representativo das etapas da pesquisa

\subsection{Participantes}

Os participantes, os objetos desta pesquisa, serão 10 estudantes com autismo de escolas do município de Juazeiro do Piauí. Esse número é parcial. Com levantamento final espera-se ter o número exato.

Para esses estudantes bem como suas famílias, espera-se que tenham acesso a internet. Exceto na escola, de forma ainda inconstante. Além disso, as avaliações serão aplicada com 4 professores que atuam diretamente com estudantes com autismo. Esses professores têm formação superior e possuem conhecimento básicos com tecnologias.

\subsection{Procedimentos}

A primeira etapa da pesquisa será feita em todas escolas do município. Pretende-se realizar um levantamento do quantitativo de estudantes com autismo em sala de aula. Será feito uma entrevista com cada estudante com autismo e/ou com seus responsáveis. Isso será a primeira coleta de dados desta pesquisa.

De posse das informações levantadas na primeira etapa, o procedimento seguinte será realizar uma avaliação com os software citados no referencial teórico: $m T e a$, o 
SCALA e o $A B C$ autismo. Será feito uma investigação com cada aluno com autismo utilizando verificando as vantagens e carências de cada software. Esse resultado faz parte da segunda coleta de dados dessa pesquisa. A investigação será feita aplicando os softwares citados no referencial teórico, comparando-os com base em suas funcionalidades oferecidas.

Por conseguinte, com os dados coletados nas etapas anteriores, pretende-se analisá-los com pedagogos e psicólogos. Essa análise avaliará se esses softwares favorecem o ensino individualizado de estudantes com autismo. Essa investigação leva em consideração as informações coletadas do estudante e suas peculiaridades.

Por fim, com o produto da investigação feita nas duas etapas citadas, pretende-se desenvolver um software que apoie e gerencie as atividades do estudante com TEA. Essa ferramenta terá como requisitos, as informações consolidadas nas $1^{\mathrm{a}}$ e $2^{\mathrm{a}}$ etapas.

\section{Ambiente Digital Proposto}

A ferramenta proposta seguirá os requisitos consolidados nas etapas anteriores. A versão inicial do software para dispositivos móveis terá quatro opções:

i) Tarefas: as atividades elaboradas pelos professores conforme o repertório de cada um;

ii) Professor: acesso para o professor elaborar as tarefas customizadas conforme o repertório de cada estudante com TEA;

iii) Pais: acesso para os pais visualizar o desempenho de seus filhos e

iv) relatórios que visa ilustrar por meio de gráficos e pequenas planilhas todo o histórico de atividades e interações de alunos, dos professores e acompanhamento dos pais.

A versão inicial, ilustrada na Figura 2, a seguir, é um protótipo da ferramenta.

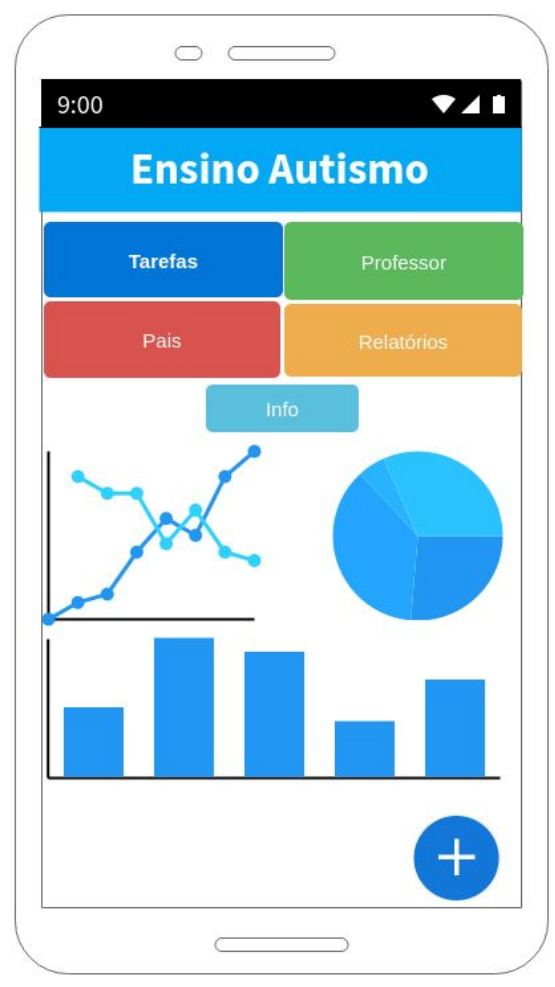

Figura 2: Layout da proposta de software 


\section{Considerações Finais}

Esta pesquisa propôs uma alternativa de estratégias de ensino para crianças com TEA com uso de dispositivos móveis. Essa alternativa visa acompanhar e gerenciar via software as atividades de ensino de cada criança com autismo.

O diferencial desta proposta, além de ser específico para o contexto dos estudantes com autismo de Juazeiro do Piauí, almeja acompanhar a evolução da criança por meio do gerenciamento das atividades digitais. A proposta pretende validar a inclusão desses indivíduos por meio de mídias digitais. Como trabalhos futuros objetiva-se desenvolver e avaliar o ambiente digital proposto.

\section{Referências}

APA. American Psychiatric Association. Diagnostic and statistical manual of mental disorders. 5th ed. Arlington, VA: American Psychiatric Publishing, 2013.

ALVES, M. M. C; LISBOA, D. O; LISBOA, D. O. Autismo e inclusão escolar. In: IV Colóquio Internacional Educação e Contemporaneidade. Laranjeiras - SE. 2010.

BITTENCOURT, Ivanise; FUMES, Neiza. A tecnologia assistiva SCALA na promoção de narrativas de sujeitos com Transtorno do Espectro Autista sobre as suas experiências escolares e o autismo. Brazilian Symposium on Computers in Education (Simpósio Brasileiro de Informática na Educação - SBIE), [S.1.], p. 767, nov. 2016. ISSN 2316-6533. Disponível em: link. Acesso em: 11/mar. 2020

CARVALHO, Lukas Teixeira; CUNHA, Mônica. 123 Autismo: Um aplicativo móvel para auxiliar no ensino de habilidades iniciais da matemática a crianças com autismo. Anais dos Workshops do Congresso Brasileiro de Informática na Educação, [S.1.], p. 1172, nov. 2019. ISSN 2316-8889. Disponível em: Link Acesso em: 11 jul. 2020.

GOMES, C. G. S., Varella, A. A. B., \& de Souza, D. G. . Equivalência de estímulos e autismo: Uma revisão de estudos empíricos. Psicologia: Teoria e Pesquisa, 26, 729-737. doi:10.1590/S0102-37722010000400017, 2010

GOMES, Camila Graciella Santos; DA SILVA CARVALHO, Brunna Stella; DE SOUZA, Deisy das Graças. Aspectos relevantes do ensino de leitura para pessoas com transtornos do espectro do autismo. em foco, p. 59, 2014.

PIMENTEL, Ana Gabriela Lopes. Autismo e escola: perspectiva de pais e professores. 2013. Tese de Doutorado. Universidade de São Paulo.

SILVA, Martony; SOARES, André; BENITEZ, Priscila. Ambiente Digital para Ensino e Acompanhamento Personalizado de Estudantes com Autismo: proposta com Uso de Dispositivos Móveis. Brazilian Symposium on Computers in Education (Simpósio Brasileiro de Informática na Educação - SBIE), [S.1.], p. 1047, out. 2017.

FARIAS, E. B. ; SILVA, L. W. C. ; CUNHA, M. X. C. . ABC AUTISMO: Um aplicativo móvel para auxiliar na alfabetização de crianças com autismo baseado no Programa TEACCH. In: X Simpósio Brasileiro de Sistemas de Informação, 2014, Londrina - PR. Disponível em <https://goo.gl/5swXXf>, acesso em 04 Mar 2015. 